\title{
Penyuluhan Kesehatan Masyarakat untuk Meningkatkan Kesehatan Keluarga di Desa Krajan Sukoharjo
}

\author{
Rukayah, Jenny Indrastoeti Siti Poerwanti, Siti Istiyati, Sularmi, SriMarmoah \\ Universitas Sebelas Maret \\ email: rukayah@staff.uns.ac.id
}

\begin{abstract}
Abstrak
Pengabdian ini ditujukan untuk anggota PKK Desa Krajan Sukoharjo dalam rangka meningkatkan kesehatan keluarga. Tujuan pengabdian ini adalah agar para anggota PKK dapat mengetahui manfaat dalam menjaga kebersihan lingkungan masyarakatdan mampu meningkatkandan menjaga kebersihan lingkungan masyarakat terutama keluarga. Pengabdian ini dilaksanakan melalui metode ceramah dan diskusi. Hasil pengabdian sampai awal September 2019 ini adalah 1) terlaksananya pemaparan tentang kesehatan kepada ibu-ibu PKK di DesaKrajan Kecamatan Gatak Kabupaten Sukoharjo untuk meningkatkan kesehatan keluarga; 2) tanya jawab dan diskusi tentang kesehatan keluarga; 3) simulasi membersihkan ruangan tempat pertemuan dan dilanjutkan ke halamannya, kemudian dipisah-pisah antara sampah organik dan non organik.
\end{abstract}

Kata Kunci: kesehatan masyarakat, kesehatan keluarga, penyuluhan

\section{PENDAHULUAN}

Pemeliharaan dan perlindungan kesehatan sangatlah penting untuk mencapi derajat kesehatan dan kesejahteraan yang tinggi. Namun kenyataan rendahnya derajat kesehatan masyarakat disebabkan oleh ketidakmampuan mereka untuk mendapatkan pelayanan kesehatan, karena mahalnya biaya kesehatan yang harus dibayar oleh masyarakat. Kesehatan merupakan investasi bagi masyarakat, sebab kesehatan merupakan modal dasar yang sangat diperlukan oleh segenap masyarakat untuk dapat beraktivitas sesuai dengan tugas dan tanggung jawabnya masing-masing, sehingga mampu menghasilkan sesuatu yang bermanfaat bagi diri sendiri dan keluarga. Namun, bila kondisi kesehatan bermasalah bukan tidak mungkin seluruh hart kekayaan akan habis digunakan untuk memperoleh kesehatan tersebut.

Kondisi kesehatan masyarakat Indonesia pada saat ini dapat dikatakan dalam kondisi yang sudah semakin membaik, meskipun masih ada sebagian masyarakat yang hidup jauh dari pola hidup sehat. Usaha masyarakat yang terorganisir untuk meningkatkan sanitasi lingkungan, kontrol infeksi di masyarakat, pendidikan individu tentang kebersihan perorangan, pengorganisasian pelayanan medis dan perawatan, pencegahan penyakit dan pengembangan aspek sosial, akan mendukung setiap orang di masyarakat mempunyai standar kehidupan yang kuat untuk menjaga kesehatannya.Salah satu ruang lingkup kesehatan masyarakat yang menjadi sorotan di Indonesia adalah yang berkaitan dengan kebersihan lingkungan dan gizi masyarakat. Pembhasan berkaitan dengan kebersihan lingkungan dan gizi memang menjadi hall menarik, karena masih banyak masyarakat yang kurang memperhatikan kebersihan lingkungannya dan dalam pemenuhan gizinya belum mendekati normal, artinya angka kecukupan gizi di masyarakat

Indonesia terutama di pedesaan masih sangat rendah. Pentingnya kesehatan 
masyarakat harusbenar-benar mendapatkan perhatian, karena masyarakat bisa menjadi cerminan suatu negara. Negara bisa terus berkembang karena ada masyarakat yang menyumbangkan SDM-nya. Sumber daya manusia yang baik tentu dari masyarakat yang sehat. Cara membentuk kesehatan yang handal suatu bangsa ditentukan oleh ketersediaan sumber daya manusia (SDM) yang berkualitas, yaitu SDM yang memiliki fisik tangguh, mental kuat, kesehatan prima, dan cerdas.Sistem Kesehatan Nasional menyebutkan bahwa tujuan pembangunan kesehatan adalah tercapainya kemampuan hidup sehat bagi setiap penduduk agar terwujudderajat kesehatan yang optimal sebagai salah satu unsur kesejahteraan umum.

Dalam rangka mencapai tujuan tersebut dilakukan upaya kesehatan yang menyeluruh, terpadu dan merata yangdapat diterima dan terjangkau oleh seluruh masyarakat dengan peran serta aktif masyarakat (SKN, 2009).Dalam rangka meningkatkan dan kualitas kesehatan masyarakat yang terkait dengan kebersihan lingkungan dan pemenuhan gizi masyarakat, maka tim P2M mengadakan sosialisasi kesehatan masyarakat pada ibu-ibu di Krajan Sukoharjo bekerja sama dengan nara sumber dari Puskesmas setempat.

\section{METODE}

Dalam mengatasi permasalahan di atas, digunakan pendekatan kolaboratif, yaitu bersama- sama dengan mitra merencanakan metode dan waktu yang tepat dalam melaksanakan suatu pelatihan. Metode yang digunakan antara lain ceramah, diskusi, simulsi, demonstrasi. Metode ceramah digunakan dalam pengabdian ini untuk menyampaikan materi sosialisasi tentang kesehatan masyarakat pada ibu-ibu PKK di Desa Krajan Sukoharjo. Metode diskusi digunakan untuk mengetahui kiatmenjaga kebersihan lingkungan. Metode simulasi dan demonstrasi untuk berlatih membersihkan sampah dan memisah-misahkan ke sampah organik dan non organik.

\section{HASIL DAN PEMBAHASAN}

Kegiatan Pengabdian yang dilaksanakan dengan acara tatap muka dan praktek pengembangan media pembelajaran berjalan dengan baik dan lancar. Pertemuan tatap muka dengan metode ceramah dan demonstrasi, dilanjutkan latihan/praktek untuk melakukan simulasi kebersihan.,

Hasil kegiatan Pengabdian secara garis besar mencakup beberapa komponen sebagai berikut: (1). Keberhasilan target jumlah peserta pelatihan, (2).Ketercapaian tujuan pelatihan (3). Ketercapaian target materi yang telah direncanakan (4). Kemampuan peserta dalam penguasaan materi

Hasil kegiatan Pengabdian pada Masyakat sampai awal September 2019 ini adalah (1) terlaksananya pemaparan tentang kesehatan kepada ibu-ibu PKK di Desa Krajan Kecamatan Gatak Kabupaten Sukoharjo untuk meningkatkan kesehatan keluarga. Hal-hal yang disampaikan meliputi (a) pentingnya kesehatan masyarakat; (b) manfaat menjaga kebersihan lingkungan;(c) upaya menjaga kebersihan lingkungan; dan (d) cara menjaga kebersihan lingkungan.

Setelah selesai pemaparan materi dilanjutnya dengan tanya jawab dan diskusi 
tentang kesehatan keluarga. Selanjutnya simulasi membersihkan ruangan tempat pertemuan dan dilanjutkan ke halamannya, kemudian dipisah-pisah antara sampah organik dan non organik.Dengan pemaparan materi tersebut diharapkan dapat meningkatkan pemahaman dan kemampuan masyarakat untuk menjaga lingkungannya. Ibu-ibu anggota PKK Desa Krajan Kecamatan Gatak Kabupaten Sukoharjo tampak antusias mengikuti pemaparan materi. Hal tersebut tampak ketika tanya jawab dan diskusi, banyak ibu yang bertanya atau menanggapi materi yang disampaikan para penyaji, diantaranya lbu Musanah bertanya tentang ciri-ciri lingkungan yang sehat, sedangkan lbu Kartini bertanya tentang lingkungan yang tidak sehat. Begitu pula lbu Siti Suryani yang menanyakan tentang kiat-kiat menjaga lingkungan agar tetap sehat.

Berdasarkan tanya jawab dan diskusi tersebut, tampak bahwa para ibu anggota PKK Desa Krajan Kecamatan Gatak Kabupaten Sukoharjo termotivasi untuk menjaga kesehatan keluarganya.Pada kegiatan simulasi, para peserta dibentuk kelompok untuk mempraktikkan kegiatan menjaga kesehatan lingkungan, yang dimulai dari ruangan tempat pertemuan yaitu mengumpulkan/membersihkan sampah dan memasukkan ke kantong sampah. Hal tersebut dilanjutkan ke halaman Balai Desa (tempat pertemuan). Sampah-sampah tersebut dipisah-pisah antara sampah organik dan non organik.

\section{KESIMPULAN}

Kegiatan pengabdian pada masyarakat ini dimulai bulan Juni 2019.Sampai dengan awal September ini kegiatan yang terlaksana adalah (1) penyampaian materi tentang kesehatan untuk meningkatkan kesehatan keluarga; (2) tanya jawab dan diskusi tentang kesehatan keuarga; dan (3) simulasi membersihkan sampah dan memisahkan antara sampah organik dan non organik.

Program simulasi dapat diselenggarakan dengan baik dan berjalan dengan lancar sesuai dengan rencana kegiatan yang telah disusun meskipun belum semua peserta simulasi menguasai dengan baik materi yang disampaikan. Kegiatan ini mendapat sambutan sangat baik terbukti dengan keaktifan peserta mengikuti simulasi dengan tidak meninggalkan tempat sebelum waktu pelatihan berakhir. $90 \%$ peserta aktif dalam diskusi kelompok, dan $95 \%$ peserta latihan antusias dalam mengikuti kegiatan simulasi kebersihan.

\section{DAFTAR PUSTAKA}

Afandi dan Sajidan. (2018). Stimulasi Keterampilan Berpikir Tingkat Tinggi (Konsep dan Implementasinya dalam Pembelajaran Abad 21). Surakart: UNS Press.

Fanani, A., \& Kusmaharti, D. (2018). Pengembangan Pembelajaran Berbasis HOTS (Higher Order Thinking Skill) di Sekolah Dasar Kelas V. Jurnal Pendidikan Dasar, 9(1), 1 - 11.

http://www.depkes.go.id/article/view/16111500002/germas-wujudkan-indonesiasehat.html

https://bulelengkab.go.id/detail/artikel/menjaga-kesehatan-lingkungan-kita-dan-sekitarIstiyono, E., Mardapi, D., \& Suparno. (2014). Pengembangan Tes Kemampuan Berpikir Tingkat Tinggi Fisika (PysTHOTS) peserta didik SMA. Jurnal Penelitian Dan Evaluasi Pendidikan, 18(1), 1-12. 
Lampiran Peraturan Presiden Republik Indonesia Nomor 2 Tahun 2015 Tentang Rencana Pembangunan Jangka Menengah Nasional 2015-2019.

Merril, Melanie T. (2012). Pembelajaran Aktif yang Menginspirasi: Buku Pegangan Lengkap untuk Guru Masa Kini, Edisi 2. Jakarta: PT. Indeks.

Usmaedi. (2017). Menggagas Pembelajaran HOTS pada Anak Usia Sekolah Dasar. Jurnal Pendidikan Sekolah Dasar, Vol. 3 No. 1, Maret 2017.

Yuniar, M., Rakhmat, C., dan Saepulrohman, A. (2015). Analisis HOTS (High Order Thinking Skills) pada Soal Objektif Tes dalam Mata Pelajaran IImu Pengetahuan Sosial (IPS) Kelas V SD Negeri 7 Ciamis. Pedadidaktika: Jurnal IImiah Pendidikan Guru Sekolah Dasar, Vol. 2, No. 2, Tahun 2015. 